\title{
Las crisis trastocan el inmovilismo y ortodoxia del Banco Central Europeo*
}

\author{
Crisis Have Obliged European Central Bank \\ to Move Away from its Immobility and Orthodoxy
}

\author{
Francisco Rodríguez Ortiz \\ Universidad de Deusto
}

doi: 10.18543/ced-54-2016pp155-178

\begin{abstract}
Sumario: I. Introducción.-II. Salida de crisis frágil e irregular apoyada en las actuaciones del BCE.-III. Cambio de sesgo de la política monetaria norteamericana: dilema para los demás bancos centrales.IV. Crisis financiera y de la deuda: tímido cambio de sesgo de la política monetaria europea.- V. El BCE se torna más atrevido...cuando menos se necesita.-VI. Conclusiones.-Bibliografía.
\end{abstract}

Resumen: Las crisis financiera y económica han desembocado en una grave crisis de las finanzas públicas. Esta sucesión de crisis ha puesto a prueba la capacidad de la política monetaria para responder a las mismas. El Banco Central Europeo ha sacralizado más que ningún otro gran banco central la estabilidad de los precios erigida en la razón de ser primera de su independencia. Solo se ha decidido a actuar como prestamista de último recurso, apelando a medidas no convencionales de política monetaria, cuando ha percibido que la zona euro amenazaba con adentrarse en una nueva recesión, que los riesgos de deflación eran crecientes y que estos factores, unidos a la crisis griega, amenazaban la propia supervivencia del euro. Sin embargo, al actuar en estado de soledad, la política monetaria europea no podrá resolver los problemas de crecimiento de la zona euro.

Palabras clave: Crisis, euro, política monetaria, independencia, deuda.

Abstract: Both, financial and economic turmoil have ended up in a serious crisis of public finances. This succession of crises has challenged ability from monetary policy to face them. European Central Bank has sacralised price stability as the core of its independence. It only decided to stand-up as lender of last resort through the implementation of non conventional monetary policies when it perceived that the mixture of Eurozone entering into a new recession alongside rising deflation risks and Greek crisis were menacing Euro currency survival. However, provided it is acting in loneliness, monetary policy will not be able to solve lack of structural growth prospects in the Eurozone.

Keywords: Crisis, Euro, monetary policy, independence, debt.

* Recibido el 1 de septiembre de 2015, aceptado el 27 de enero de 2016. 


\section{Introducción}

La zona euro, pese a ser presentado el proyecto de moneda única como factor de dinamización de las economías, se halla desde los años ochenta en una situación prolongada de «crecimiento blando» ${ }^{1}$, cuando no de recesión. Además, no solo la moneda única no ha aminorado las disparidades entre los EEMM (Estados Miembros), como se argumentó cuando fue ideado el proyecto, sino que se ha logrado lo contrario. La solidaridad intracomunitaria se debilita, el crecimiento potencial es exangüe, las ganancias de productividad son escasas, la distribución de la renta es cada vez más desigual debido al paro creciente, precariedad laboral, bajos salarios, recortes de prestaciones sustitutorias etc. y la dominación alemana ha devenido hegemonía. «En lugar de favorecer la resolución de los desequilibrios en el seno de la zona euro, los principios neoliberales han tendido a incrementar las divergencias entre los países, algunos de los cuales se han hallado colocados en situación insostenible» ${ }^{2}$. La realidad se ha encargado de demostrar que resultaba voluntarista la idea según la cual constituir una unión monetaria irrevocable entre economías estructuralmente dispares no iba a generar grandes sobresaltos en ausencia de un proyecto de unión política previa. La renuncia a la moneda nacional para formar parte de un sistema único con fuertes disparidades de productividad, sin mecanismos fiscales compensatorios, hace que sólo sobrevivan los sectores y empresas capaces de desgajar mayores ganancias de productividad ${ }^{3}$. Las heterogeneidades, desequilibrios y desindustrialización de los más débiles, lejos de remitir se acentúan ${ }^{4}$.

«Debido a que el mercado interior europeo ha incrementado considerablemente la dimensión de la demanda, esta ha beneficiado al máximo a las industrias ya dominantes como consecuencia de los rendimientos crecientes a escala. El incremento de la demanda ha incrementado la rentabilidad de las empresas ya instaladas; lo que ha generado unas inversiones de aumento de escala y modernización que han permitido extraer unos progresos de productividad que han alimentado el incremento de las rentas reales del que depende el auge endógeno de la demanda. Resulta pues lógico que los países del norte de Europa hayan mejorado su

${ }^{1}$ Este concepto se aproxima al de «estancamiento secular» acuñado por Larry Summers.

${ }^{2}$ COSSART, J., DOURILLE-FEER, E., HARRIBEY, J.M., HUSSON, M., JEFFERS, E., KHALFA, P., MATH, A., PLIHON, D. y TOUSSAINT, E., Le piège de la dette publique, Les Liens qui Libèrent, París, 2011, p. 94.

3 ANGUSTO, J., ¿Y ahora qué? Entre la crisis y la miseria: propuestas alternativas, Gregal, Barcelona, 2013.

${ }^{4}$ RODRÍGUEZ ORTIZ, F., La Unión Monetaria y España: ¿Integración económica o desintegración social?, Ed. Universidad de Deusto, Bilbao, 1997. 
ventaja inicial respecto de los países del sur y que ello haya provocado su desindustrialización» 5 .

Asimismo, se consideró erróneamente que los saldos corrientes individuales dejaban de ser relevantes. Sin embargo, como señala Martin Wolf:

«Dado que se ha eliminado el ajuste por el tipo de cambio, puede decirse que la balanza de pagos importa incluso más dentro de una unión monetaria de lo que importa para países independientes con monedas fluctuantes y sus propios bancos centrales. Una vez que un país dentro de una unión monetaria se vuelve dependiente de grandes flujos entrantes netos de capitales, un giro súbito en estos flujos causará una crisis económica. Esta crisis estará marcada por un shock financiero, al ser retirada la financiación externa, y una depresión profunda al no poder financiarse las importaciones en las que la economía había confiado. El impacto de la crisis es también muy asimétrico: para los países con superávit, es un inconveniente ya que el valor de sus derechos financieros en países con déficit se vuelve incierto; pero para los países con déficit, es un asunto de vida o muerte económica, ya que el impacto a corto plazo de una retirada súbita de financiación externa devasta la economía» 6 .

Los países europeos se han instalado desde los años ochenta en una crisis prolongada de crecimiento, un estancamiento-retroceso de los salarios reales y un empeoramiento de las desigualdades. Según Martín Seco, «la Unión Europea y Monetaria es el proyecto más claro de insurrección del capital frente al Estado social» ${ }^{7}$. Pero este incremento de las desigualdades no es accidental. Es el «fruto envenenado de una concepción particular de la «virtud económica» que coloca en el corazón de las políticas públicas a la competencia fiscal y social» ${ }^{8}$. Los efectos negativos asociados a la creciente moderación salarial inducida por el nuevo credo neoliberal que se impone en toda Europa, más allá de los supuestos anclajes ideológicos de sus gobernantes, han sido contrarrestados apelando al endeudamiento generalizado de los varios agentes privados. El nuevo régimen de acumulación pasa a ser particularmente frágil y vulnerable al requerir una política monetaria acomodaticia de bajos tipos de interés. Pero, según expresara Paul Volcker,

5 AGLIETTA, M., Zone euro: éclatement ou fédération, Michalon, París, 2012, p. 128.

6 WOLF, M., La gran crisis: cambios y consecuencias, Ed. Deusto, Barcelona 2015, p. 114.

7 MARTÍN SECO, J.F., Contra el euro: historia de una ratonera, Península, Barcelona, 2013, p. 43.

${ }^{8}$ FITOUSSI, J.P., Le théorème du lampadaire, Les Liens qui libèrent, París, 2013, p. 106. 
«Demasiada liquidez en el mercado puede llevar a los inversores a asumir demasiados riesgos, mediante un encarecimiento de los precios de los activos, inmersos en la creencia que siempre habrá un comprador de buena voluntad. A cierto nivel, la liquidez o la percepción de que no va a faltar puede favorecer un trading más especulativo» ${ }^{9}$. La política monetaria, error que podría estar reproduciéndose en la actualidad, no presta la debida atención a la evolución del precio de los activos financieros y tiene dificultades para adecuarse a la importancia adquirida por las finanzas. Las nuevas condiciones de acumulación hacen particularmente obsoleta la concepción de la estabilidad monetaria del BCE (Banco Central Europeo) al cambiar radicalmente los mecanismos de transmisión de la inflación que, debido a la concatenación de muchos factores, ha dejado de ser un peligro a corto y medio plazo $^{10}$. El nuevo capitalismo financiero exige que el BCE sea más reactivo a la inflación de los activos financieros y no ya simplemente al nivel general de los precios al consumo ${ }^{11}$.

La financiarización de la economía ha tendido a debilitar el Estado frente al poder ascendente de los mercados financieros. Esta situación se visualiza aún más tras el estallido de la crisis de la deuda soberana que ha reforzado el papel del BCE, entidad «supranacional» sustraída por Tratados al poder de control de los gobiernos y única con capacidad para responder a unas crisis que afectan la credibilidad y perdurabilidad del euro. ¿Ha sabido encarar el BCE la crisis financiera entre 2007 y 2008, la crisis económica entre 2009 y 2010 y luego la crisis de las deudas soberanas? Su actuación ha sido más timorata que la de la Reserva Federal, Banco de Inglaterra o Banco de Japón y ha cometido muchos errores en cuanto a diagnóstico, gestión de los tiempos y terapias impuestas a los Estados para «ayudarlos», cuando no acogotarlos un poco más. Sin embargo, la percepción de que una nueva recesión era posible y que la zona euro estaba flirteando con una peligrosa deflación han obligado al BCE, que no ha sabido «preservar los bienes públicos que son la moneda y la estabilidad financiera, como queda demostrado por una crisis mucho más profunda y duradera en la zona euro que en Estados Unidos» ${ }^{12}$, a alterar los instrumentos y sesgo de la política monetaria común entre julio de 2012 y enero de 2015.

9 GREAU, J.L., La Grande Récession (depuis 2005), Folio, París, 2012, p. 199.

10 RODRÍGUEZ ORTIZ, F., Crisis de un capitalismo patrimonial y parasitario, Los Libros de la Catarata, Madrid, 2010, pp. 103-109.

11 BOYER, R., Les financiers détruiront-ils le capitalisme ?,Economica, París 2011, p. 183.

12 JEFFERS, E., LE HERON, E. y PLIHON, D., «Pour une banque centrale européenne au service de l'intérêt général» en Changer l'Europe, Les Économistes Atterrés, Les Liens qui Libèrent, París, 2013, pp. 239-256, p. 251. 


\section{Salida de crisis frágil e irregular apoyada en las actuaciones del BCE}

La salida de la crisis está dando lugar a un crecimiento inferior y más irregular que el de ciclos anteriores y no permite subsanar el paro masivo en la eurozona. La zona euro ha salido de su segunda recesión en el segundo semestre de 2013 y el crecimiento, tras un año 2014 muy incierto, se acelera en 2015. La caída del precio del crudo, la fuerte depreciación del euro impulsada por las medidas de QE (QuantitativeEasing) anunciado por el BCE en enero de 2015, llamado a ser mantenido, por lo menos, hasta septiembre de 2016, la mejora de las condiciones crediticias, la rebaja de las primas de riesgo país, lo que permite relajar la presión adversa del ajuste fiscal, actúan como factores que permiten dinamizar el crecimiento. Este cambio de escenario debe mucho a que el BCE ha tenido que romper con su relativo inmovilismo a partir de junio de 2014, para responder a la apreciación de la moneda europea respecto de las principales monedas, así como para atajar los crecientes riesgos deflacionistas, agravados por la propia apreciación de la moneda europea. De adentrarse la zona euro en un escenario deflacionista, más factible a partir del verano de 2015 una vez estallan las crisis económicas y cambiarias de China y de las economías emergentes y se acentúa la caída del precio de las materias primas, se vería impedido el proceso de desendeudamiento privado y público. Como señalan O'Rourke y Taylor, «las grandes deudas públicas son difíciles o imposibles de estabilizar cuando la deflación aumenta el valor real de la deuda y ralentiza el crecimiento económico» ${ }^{13}$. Asimismo, Olivier Blanchard, economista jefe del FMI (Fondo Monetario Internacional), destacaba en enero de 2014, al presentar el Informe de perspectivas del FMI, que aunque sus previsiones pasan por una tasa positiva de crecimiento de los precios, «el riesgo es que la inflación se convierta en deflación. Y aunque no hay nada mágico sobre el número cero, cuanto más baja sea la tasa de inflación, más peligrosa será para la eurozona». Sin embargo, al estar los tipos de intervención del BCE en cero, al igual que en los principales bancos centrales del mundo, dispone de un menor margen de maniobra respecto de otras crisis para atajar el riesgo de deflación, y las llamadas medidas «no convencionales» de expansión cuantitativa surten menos efectos y sus resultados son más inciertos en lo que respecta a la dinamización de la economía.

La fragilidad de la recuperación llevaba no obstante a la OCDE (Organización para la Cooperación y el Desarrollo Económico) y al FMI a recomendar, a partir de 2014, que el BCE apoyara la demanda impulsando las

13 O'ROURKE, K. y TAYLOR, A., «Cross of euros» en Journal of Economic Perspectives, vol. 27, n. 3 , 2013, pp. 167-192, p. 176. 
políticas monetarias no convencionales tanto más manejables cuanto que el paro es masivo y son inexistentes las presiones inflacionistas. Paradójicamente, siguen urgiendo a proseguir con las llamadas reformas estructurales que sesgan contra la propia demanda que se pretende alentar por la vía monetaria. La Directora Gerente del FMI reclamaba en el discurso previo a la reunión de primavera del FMI y el Banco Mundial, en abril de 2014, que el $\mathrm{BCE}$ recurriera «a medidas de política monetaria no convencionales». «Una flexibilización adicional de la política monetaria en la eurozona es necesaria para elevar las perspectivas y lograr el objetivo de estabilidad de precios del BCE». Temía que «un periodo potencialmente prolongado de baja inflación pudiese reprimir la demanda, el crecimiento y el empleo». Luego, el Informe del FMI recogía que «dado el débil y frágil crecimiento y la inflación muy baja, son necesarios más estímulos monetarios para alcanzar los objetivos de inflación del BCE, por debajo pero cerca del 2\%». En la reunión de Jackson Hole, foro de bancos centrales, mantenida en agosto de 2014, el Presidente del BCE se desmarcaba de los gobernantes europeos renuentes a entonar un mea culpa por el diagnóstico y políticas erróneas. Señalaba que había de ser cambiado el paso y reconocía, sí bien tardíamente, los límites de las políticas de oferta ensayadas desde 2010. Admitía que Europa estaba confrontada a una demanda agregada insuficiente, para lo que el BCE se preparaba para transferir liquidez abundante al mercado supeditada a que este la trasladara a las empresas y particulares. A tal punto era delicada la situación que el Presidente del BCE reconocía ante el PE (Parlamento Europeo), a finales de septiembre de 2014, que el crecimiento se «hallaba en punto muerto» y anunciaba más medidas no convencionales. Proponía una acción centrada en la apertura de tres frentes simultáneos: estímulos monetarios y fiscales, inversión a escala europea y reformas estructurales ${ }^{14}$. Estos pronunciamientos unidos al deterioro de las expectativas de crecimiento europeo, deterioro de la situación en Grecia, y al cambio de sesgo de la política monetaria norteamericana iban a contribuir a iniciar el proceso de depreciación del euro ${ }^{15}$.

14 AGLIETTA, M. y BRAND, T., Un New Deal pour l'Europe, Odile Jacob, París, 2013, pp. 249-289. El ajuste fiscal habría de ser flexibilizado y diferenciado según los países. Aquellos con mayor margen de acción habrían de acometer inversiones de infraestructuras. Queda la nebulosa de lo que cabe ser recogido bajo el concepto de «reformas estructurales» sin las cuales, según Draghi, «la política monetaria por sí sola no puede producir crecimiento». Y, más importante, intuyéndose su contenido, ¿hasta qué punto son compatibles con una necesaria dinamización de la demanda interna?

${ }^{15} \mathrm{La}$ insensatez de las políticas de ajuste impulsadas en Europa y la política del BCE han contribuido a una apreciación excesiva del euro. Ha anulado en la periferia europea, gran parte de las «ventajas» competitivas logradas mediante la reducción de los costes salariales. Desde que fijara su tipo de cambio en 1,20 dólares en el verano de 2012, el euro se había apreciado un 14\% frente al dólar en julio de 2014. 
Esa depreciación, favorable para las exportaciones y para frenar las presiones deflacionistas, se acentuaría cuando se confirmó que el BCE iniciaba su propio QuantitativeEasing. Se evidenció que la política de restricción salarial fuerte y generalizada, que no impide el paro masivo en la eurozona, estrategia a la que están aferrados los miembros de la antaño llamada Troika, hoy rebautizada como «Instituciones», no es un sustituto aceptable a la inacción cambiaria ${ }^{16}$. Esta represión salarial en los países avanzados no sólo incide negativamente en la demanda interna, sino que somete a una mayor presión adversa a medio plazo la financiación del sistema de pensiones por reparto. Ello lastra el desarrollo del Estado del bienestar e impide, salvo que se produzca un improbable crecimiento álgido, que la política presupuestaria actúe como factor de dinamización de la economía. Pero, presa de su ideología neoliberal, una de cuyas expresiones es la sorprendente «restricción presupuestaria expansiva», las autoridades europeas son renuentes a aceptar que al ocultarse tras la crisis financiera una crisis keynesiana de insuficiencia de demanda solvente a nivel mundial, la política monetaria no es suficiente y que dar continuidad al crecimiento requiere, como mínimo, impulsar un nuevo pacto keynesiano de rentas ${ }^{17}$. Siendo muy negativos los factores que influyen sobre el crecimiento potencial, Wolf, Economista Jefe del Financial Times, sostiene que «los países desarrollados no se pueden permitir años, incluso décadas, de estancamiento innecesario, debido a demandas inadecuadas ${ }^{18}$. Aboga, consciente no obstante de que volver al pleno empleo a través de políticas de estímulo no resolverá los problemas de las economías centrales, por unas políticas monetarias ultra-acomodaticias acopladas a abultados déficits públicos. «Ello reduciría la desgracia inmediata. No se puede permitir que lo mejor sea enemigo de lo bueno» ${ }^{19}$. En su opinión, evitar un crecimiento explosivo de la deuda obligaríaa afrontar la debilidad estructural de la demanda imprimiendo dinero y gravando el ahorro en lugar de, como ha hecho Japón o se impone a Grecia, subir el IVA. Los bancos centrales financiarían directamente los déficits.

\section{Cambio de sesgo de la política monetaria norteamericana: dilema para los demás bancos centrales}

Una de las mayores dudas que condicionan el recorrido de la economía mundial y la actuación de los demás bancos centrales va asociada a los

\footnotetext{
16 ARTUS, P. y GRAVET, I., La crise de l'euro, Armand Colin, París, 2012, p.138.

17 WOLF, M., op. cit.,nota 6, pp. 403 y siguientes.

18 WOLF, M., op. cit.,nota 6, p. 406.

19 WOLF, M., op. cit.,nota 6, p. 409.
} 
efectos inducidos por un incremento de los tipos de interés en Estados Unidos. A finales de junio de 2013, el BIS (Banco Internacional de Pagos de Basilea) presentaba su Informe anual y cuestionaba la estrategia seguida por los bancos centrales. Su Director General, Jaime Caruana, entendía que peligraba la estabilidad financiera a nivel mundial y pedía poner fin a sus políticas de crecimiento de balance, una estrategia que habría de ir pareja con un esfuerzo redoblado en cuanto a consolidación presupuestaria y reducción de la deuda pública. En su opinión, los costes de la expansión monetaria rebasaban sus beneficios. El BIS afirmaba que, «no siendo monetarias las raíces del problema de crecimiento», «los bancos centrales deben reforzar su objetivo tradicional... y animar a los gobiernos a llevar a cabo los ajustes necesarios, más que retrasarlos con tipos de interés casi cero y compras aún mayores de bonos soberanos». Contradiciendo el pronunciamiento de Draghi de julio de 2012, el BIS sentenciaba que: «Está quedando cada vez más claro que los bancos centrales no pueden hacer "todo lo que haga falta" para devolver las aún débiles economías a un crecimiento fuerte y sostenible». En su Informe anual de finales de junio de 2015, reiteraba que lo excepcional no podía erigirse en rutina. Adelantaba que el carácter ultra acomodaticio de las políticas monetarias «que busca espolear la demanda», ha arraigado «la dependencia del modelo de crecimiento basado en el endeudamiento que precisamente estuvo en la raíz de la crisis». De ahí el peligro de burbujas y contracciones financieras. Para Caruana, ha llegado el momento de retirar los estímulos y reactivar los tipos de interés tanto más cuanto que «los bajos precios del petróleo imprimen un impulso significativo al crecimiento de la economía mundial, que podría respaldar una normalización continua de la política monetaria. Esta normalización podría generar cierta volatilidad en el corto plazo, pero ayudaría a contener los riesgos en un horizonte más largo». La OCDE se ha unido a partir de enero de 2015 al coro de aquellos que perciben como muy peligrosa para la estabilidad financiera las políticas monetarias ultra-expansivas llevadas a cabo. Al igual, la presidenta de la Fed (Reserva Federal norteamericana) insistía, el 27 de marzo de 2015, en que «mantener los tipos demasiado bajos durante demasiado tiempo podría incentivar una asunción de riesgos inapropiada por parte de los inversores, y minar potencialmente la estabilidad de los mercados financieros». Todos los grandes bancos centrales, incluido el BCE, tienen pues que sopesar los riesgos de un repliegue prematuro y los de seguir demorándolo a sabiendas de que la dimensión y el alcance del inevitable repliegue futuro no tienen precedentes, lo que eleva la incertidumbre. Además, la subida en la curva de tipos de Estados Unidos es susceptible de infligir grandes pérdidas a los tenedores de bonos norteamericanos así como a los de bonos de otros países si se propagaran las tensiones sobre sus tipos de interés. Ello trabaría el saneamiento del balance de los bancos y la incipiente 
recuperación del crédito. Esta bomba de relojería de los bonos es particularmente sensible en la eurozona al hallarse los tipos de interés en unos niveles históricamente bajos, y hasta negativos para muchos países en plazos cortos debido a la baja inflación y compras masivas de bonos por parte del BCE. Pero, si los bancos centrales tardan demasiado en normalizar su política monetaria, existe el riesgo de que el estímulo de los tipos bajos acabe en los mercados financieros en lugar de en la economía productiva, sí bien el BCE descarta que existan burbujas susceptibles de desestabilizar el sistema financiero. Una opinión cuando menos sorprendente vistas las inusualmente bajas rentabilidades alcanzadas por los bonos y, consecuentemente, sus elevados precios.

Ahora bien, se observa como Estados Unidos, cuya economía crece de forma irregular y cuyo saldo comercial está siendo penalizado por la apreciación del dólar, la cual contribuye a contener el crecimiento de los precios, teme acudir a una subida demasiado precoz de los tipos de interés susceptible de reproducir el error de 1937. Sin embargo, las autoridades deben pensar, tras seis años de crecimiento, en la próxima recesión. Y ahora no existe margen para bajar tipos si se produjera un deterioro de la economía. Este es el principal motivo para que la Fed empiece a normalizar el precio del dinero en septiembre de 2015. Según la hoja de ruta adelantada por los miembros del FOMC (Comité Federal de Mercado Abierto), en junio de 2015, deberían producirse dos subidas de tipos en la segunda mitad de 2015. Quedarían colocados en una horquilla que oscilaría entre el 0,5 y el $0,75 \%$. En 2017, todavía seguirán por debajo del 3\%. Estas subidas no serán mecánicas, y siempre estarán supeditadas a la evolución de la coyuntura. Y pesan las incertidumbres internacionales: Grecia y estabilidad de la eurozona, China y emergentes.

\section{Crisis financiera y de la deuda: tímido cambio de sesgo de la política monetaria europea}

El BCE, en contra de la Fed que goza solo de independencia instrumental, es independiente respecto del poder político y su estatuto de independencia va referido a garantizar la estabilidad de los precios y disciplinar los salarios. En caso de incremento indebido de estos, procederá a subir los tipos de interés. Ello enfría la actividad, eleva el nivel de paro, debilita el poder de negociación de los trabajadores y permite rebajar los salarios reales. Se entiende que según el pensamiento liberal la independencia del banco central haya de ir pareja con una desregulación radical del mercado de trabajo. El dogma de la estabilidad de los precios llevó el BCE a subir de forma inoportuna los tipos de interés en julio de 2008, (en vísperas de Le- 
hmanBrothers) y nuevamente, entre abril y julio de 2011 (en plena crisis de la deuda privada y soberana). El BCE ha obviado, hasta noviembre de 2013, que los riesgos mayores para una economía endeudada provienen de la deflación, fenómeno analizado por Irving Fischer en los años treinta. La deflación es el riesgo mayor porque si bien caen los precios y los salarios, los tipos de intereses reales son ascendentes, así como el poder adquisitivo de la moneda. Aumenta la carga real de la deuda pendiente (principal e intereses) y, en contra de lo que ocurre cuando hay cierta inflación, los agentes privados solicitan menos préstamos puesto que han de devolverlos en una moneda cuyo valor tiende a subir mientras que se contraen sus rentas. Al aumentar el coste real de los préstamos, la mora empeora, tanto más cuanto que se eleva el paro, se incrementa el número de quiebras empresariales y sigue cayendo el valor de muchos activos detentados por los bancos. Asimismo, las expectativas de mayores bajadas en los salarios y los precios llevan a una caída del consumo y retraso de las decisiones de inversión. Los consumidores e inversores conceden preferencia al ahorro respecto de la inversión. Las empresas realizan nuevos ajustes de costes en su producción que provocan mayores recortes de los salarios. Se complica la situación de unas entidades bancarias que van cayendo en situación de insolvencia al erosionarse su capital. Reaccionan restringiendo el crédito, lo que traba la refinanciación de la deuda en condiciones menos onerosas. El colapso del crédito agudiza las presiones depresivas y estas profundizan en las presiones deflacionistas. Se crea un círculo vicioso muy difícil de romper.

Además de limitarse su mandato a la estabilidad de precios, se prohíbe al BCE, en contra de lo que ocurre en Estados Unidos, Reino Unido o Japón, monetizar la deuda de los Estados. Ello refuerza el poder de los mercados financieros respecto del Estado, una limitación institucional de la zona euro denunciada de forma certera por Cossart, Husson... ${ }^{20}$ :

«Si los mercados han desencadenado sus furias contra la zona euro más que contra Estados Unidos o el Reino Unido, ello se debe a que han descubierto una falla. Mientras los gobiernos de otros países desarrollados no pueden quebrar porque siempre pueden ser refinanciados por el Banco Central, si fuera necesario mediante creación monetaria, los países miembros de la zona euro han renunciado a dicha posibilidad».

Sin embargo, la intensidad de la crisis financiera y económica ha obligado el BCE, más timorato que los otros grandes bancos centrales, a decantarse a partir de 2009 por unas políticas monetarias expansivas para sostener la actividad y proporcionar apoyo a los sistemas financieros. Aunque

${ }^{20}$ COSSART, J. et al.,op. cit., nota 2, p. 100. 
ha ido siempre a remolque de la coyuntura, ha tenido que proporcionar una liquidez abundante a las instituciones financieras. Evitaba así que tuvieran que vender unos títulos de la deuda pública que ya no lograban refinanciar y contenía la erosión de su precio, lo que hubiera dañado aún más el balance de dichas instituciones financieras. Evitaba, asimismo, un mayor deterioro de la prima de riesgo soportada por los países frágiles en las emisiones primarias. El BCE ha desplegado muchos esfuerzos para desacoplar los problemas de la deuda soberana de los balances bancarios. Pero ha sido lento de reflejos y ha ido por detrás de los acontecimientos. Lo que no es de extrañar. Las reglas constitutivas de la UME (Unión Monetaria Europea) descartan asignar al $\mathrm{BCE}$ el papel de prestamista de último recurso. El BCE no puede adquirir directamente deudas públicas en el mercado primario ni prestar a tipo cero a los Estados, a los que se prohíbe también acceder a una financiación privilegiada por parte de los bancos de segundo rango. Al tener que financiarse en los mercados financieros se les traslada un poder de control absoluto sobre la evolución de las finanzas públicas. Le Héron señala que «resulta fácil comprender las razones por las cuales los mercados financieros y las agencias de calificación han adquirido una influencia tan grande en la evolución de las deudas públicas y de sus tipos de interés a partir de los años $2000 »^{21}$. Paul de Grauwe estima que «el calendario y la intensidad de los programas de austeridad han sido determinados en exceso por el sentimiento de los mercados, en vez de ser el resultado de un proceso de decisión racional». Este poder ascendente de los mercados financieros, carencias del entramado comunitario y ambigüedades del BCE, han desembocado en una austeridad excesiva en la eurozona ${ }^{22}$. La renuencia del BCE a proveer de la liquidez necesaria a los mercados primarios de la deuda pública ha alimentado los temores a que se incumplieran las obligaciones vinculadas a los bonos soberanos, y ha contribuido a crear un bucle infernal entre deuda bancaria y deuda soberana que se empezaría a romper en julio de 2012, si bien el BCE apeló entonces más a la retórica que a medidas reales.

Las sucesivas crisis han erigido al $\mathrm{BCE}$ en la institución con más poder económico y político para responder a las mismas. Ha tenido que ser más activo tanto en los frentes convencionales como menos convencionales, tanto más cuanto que la herramienta del tipo de interés iba agotando su recorrido y que los países de la eurozona están inmersos en un proceso de reducción de los déficits. Se ha visto obligado, pese a las limitaciones insti-

${ }^{21}$ LE HÉRON, E., À quoi sert la Banque centrale européenne? La Documentation Française, París, 2013, 38.

22 GRAUWE, P. y JI, Y., «More evidence that financial markets imposed excesive austerity in the eurozone» en CEPS, 5 febrero 2013 
tucionales bajo las que opera, a ser cada vez más heterodoxo para evitar la implosión de la zona euro, salvar a los bancos privados, rebajar las primas de riesgo, evitar la amenaza creciente de deflación y devolver cierta normalidad al crédito. Ha tenido que trasladar una cantidad creciente de liquidez a la banca hasta culminar sus intervenciones en las dos operaciones (Long TermRefinancingOperation) por las cuales inyectó 1 billón de euros entre diciembre de 2011, y febrero de 2012, con un plazo inusual de vencimiento a 36 meses. Se trataba de facilitar la labor de la banca como agente activo en el mercado de la deuda soberana. Así como han hecho sus homólogos, ha rebajado la calidad de las garantías prendarias exigidas a los bancos para acceder a su liquidez. Se ha visto abocado a adquirir títulos de deuda pública y privada a las entidades financieras en los mercados secundarios para garantizar la liquidez del mercado de la deuda pública ${ }^{23}$ y rebajar el coste de emisión de la deuda primaria, situación que equivalía a una monetización indirecta de la deuda, de la que han sacado grandes beneficios los bancos que accedían en condiciones provechosas a la financiación del BCE.

«En definitiva, el BCE ha asumido el papel de prestamista de último recurso para los bancos al proporcionarles una refinanciación prácticamente ilimitada, a unos tipos cercanos a cero y de manera incondicional. Por contra, a diferencia de la Fed de los Estados Unidos y del Banco de Inglaterra, el BCE se ha negado a asumir plenamente dicho papel respecto de los Estados. Así pues, tiene una gran parte de responsabilidad en la amplitud adquirida por la crisis de la deuda soberana en la zona euro» ${ }^{24}$.

El exceso de dogmatismo que subyace a las acciones del BCE, aun cuando la realidad le ha llevado a ser más flexible, hace que el sistema financiero europeo se vea "privado de uno de sus elementos esenciales: una deuda pública sin riesgo, necesaria para el buen funcionamiento de los mercados y la existencia de una curva de tipos de interés estable» ${ }^{25}$. Presionado por Alemania, por sus propios estatutos y convicciones ideológicas, ha rehusado asumir el papel de prestamista de último recurso de los Estados, un papel asumido por los demás grandes bancos centrales. Esa situación empezó a cambiar radicalmente a partir de junio de 2014, aunque el Presidente del BCE ya había salido al paso de una situación que se deterioraba. Comunicó a los mercados, en julio de 2012, que «El BCE hará lo ne-

${ }^{23}$ BETHËZE, J.P., BORDES, C., COUPPEY-SOUBEYRAN, J. y PLIHON, D., Banques centrales et stabilité financière, Conseil d'Analyse Économique, La Documentation Française, París, 2011, p. 18.

${ }^{24}$ JEFFERS, E. et al., op. cit., nota 12, p. 248.

25 JEFFERS, E. et al., op. cit., nota 12, p. 251. 
cesario («What ever it takes») para sostener el euro. Y créanme, eso será suficiente». Un pronunciamiento que resultó suficiente para rebajar las tensiones en torno a las deudas públicas de ciertos países con dificultades para financiarse. Así, el BCE se dotaba, en septiembre de 2012, de un nuevo dispositivo: el OMT (Outright Monetary Transactions) que le permitía adquirir sin límites en los mercados secundarios títulos públicos de entre 1 y 3 años ${ }^{26}$, siempre y cuando pertenecieran a un país acogido oficialmente a una petición de ayuda del FEEF/MEDE (Mecanismo Europeo de Estabilidad). Por lo tanto, una condicionalidad estricta que implicaba reformas estructurales, más recortes y un menor margen de maniobra contracíclica para los gobiernos sometidos a los dictados de la troika. Asimismo, renunciaba, en septiembre de 2012, a su prioridad sobre el resto de acreedores en el cobro de la deuda soberana y aceptaba tener un trato idéntico al de los acreedores privados. En junio de 2014, adoptaba una serie de medidas inauditas para frenar la apreciación del euro y luchar contra la excesivamente baja tasa de inflación. El tipo de intervención fue rebajado del 0,25\% al 0,15\%, y fue dejado en el $0,05 \%$ en septiembre. Paralelamente, reactivar el crédito e impulsar algo los precios le llevó a imponer una tasa negativa a los depósitos de los bancos del $0,1 \%$, llevada al $0,2 \%$ en septiembre.

Las intervenciones desplegadas por el BCE han contribuido a reducir de forma significativa la aversión al riesgo. Así, por ejemplo, la prima de riesgo de España, que llegó a rebasar los 600 puntos en julio de 2012, se movía en torno a los 120 puntos en diciembre de 2014, un nivel en el que se mantiene con ciertas oscilaciones según evolucionan los acontecimientos en Grecia. En cualquier caso, lo cual no deja de ser paradójico, a partir de finales de 2013, excepción hecha de Grecia y de Portugal, las economías periféricas lograban financiarse más barato que antes de la crisis. El bono español a 10 años arrojaba una rentabilidad del $4,05 \%$ en $2007 ; 3,68 \%$ en enero de 2014; $2,3 \%$ en octubre y $1,83 \%$ en diciembre de 2014. Consecuencia de la crisis griega y de un cierto repunte del tipo de interés de la deuda alemana, repuntaba hasta el 2,4\% en julio de 2015, lejos del 7,5\% de julio de 2012 . El país más beneficiado sigue siendo, no obstante, Alemania. La rentabilidad de sus bonos ha caído del $4 \%$ en 2007 , al $1,1 \%$ en octubre de 2014 , $0,73 \%$ en diciembre, y en torno al $0,8 \%$ en julio de 2015 .

Asimismo, el BCE activaba un nuevo TLTRO (Targeted Long Term Refinancing Operation) entre septiembre y diciembre de 2014. Su importe ascendía a 400.000 millones de euros y su vencimiento teórico es 2018. Se le habían de sumar otras seis subastas trimestrales, entre marzo de 2015

${ }^{26} \mathrm{Al}$ concentrarse en los plazos cortos, trataba de dar salida a las ingentes posiciones de deuda acumulada en el balance de los bancos, incluidas las entidades alemanas y francesas. 
y junio de 2016, por un importe de 600.000 millones. Condicionaba estas ayudas, para evitar que las instituciones financieras retuvieran la liquidez en el propio BCE o la dedicaran a comprar deuda pública, a que laliquidez fuera convertida en créditos a las Pymes (Pequeñas y medianas empresas). De no ser así, el dinero captado habría de ser devuelto antes de 2016. Aunque no existen penalizaciones. El gran desafío del BCE es restablecer la correa de transmisión de la política monetaria. De poco sirve que reduzca los tipos y eleve la liquidez si los bancos no conceden más créditos.

\section{EI BCE se torna más atrevido... cuando menos se necesita}

La política monetaria europea ha ido cayendo en la trampa de la liquidez según se agravaba la recesión. La rebaja de los tipos oficiales fue llevada a su límite en septiembre de 2014, y ha demostrado surtir efectos limitados sobre la economía real. La soledad en la que se ha desenvuelto la política monetaria convencional no ha permitido impedir la caída de la actividad inducida por unas políticas presupuestarias y salariales muy restrictivas. Esta constatación ha desembocado en una relativa suavización de los ajustes presupuestarios respecto del rigor extremo mantenido entre mayo de 2010 y finales de 2012, así como también ha llevado al BCE, con retraso, a adentrarse en la llamada política monetaria «no convencional». Evitar la «japonización» de las economías europeas exige un policy-mix más equilibrado, cuestionar la estrategia contraproducente de devaluación salarial competitiva en los respectivos EEMM de la eurozona, lastrada además, hasta octubre de 2014, por la excesiva apreciación del euro, y asumir un verdadero programa de inversión a escala europea. Este cambio de sesgo dado a la política económica ha permitido a la zona euro retornar a un crecimiento blando. La política monetaria ha tenido que apelar finalmente a las llamadas medidas «no convencionales» para transmitir sus impulsos a la economía real. Los gobiernos y las autoridades comunitarias, pese al paro masivo e incremento de las desigualdades, aprovechaban este rebote para destacar lo acertado de las medidas adoptadas y lo caduco de las recetas keynesianas. Sin embargo, el carácter acomodaticio de la política monetaria no garantiza una mejora automática de las condiciones crediticias y abona el terreno para el desarrollo de nuevas burbujas en los precios de los activos financieros. Entonces, ¿por qué ha terminado aceptando el BCE impulsar una política no convencional que contraviene realmente el mandato que le asignan los tratados?

Al confirmarse el estancamiento en la eurozona, y no solo la ausencia de cualquier riesgo inflacionista sino un peligroso movimiento a la baja de los precios, el BCE, que no podía bajar más los tipos de interés, anunciaba, 
el 22 de enero de 2015, un sistema de compra de bonos públicos y privados por un importe de 60.000 millones de euros mensuales, entre marzo de 2015 y septiembre de 2016 (sobre todo deuda pública pero también cédulas hipotecarias y, en menor grado, titulizaciones). No era ninguna sorpresa toda vez que el BCE ya había adelantado, en noviembre de 2014, que contemplaba medidas adicionales de confirmarse los riesgos de deflación. Se interpretó que iba a iniciar un programa de compras de deuda pública y otros activos para reparar el canal de transmisión de la política monetaria, elevar la inflación, depreciar la deuda etc. Una opción cada vez más apoyada por el FMI y la OCDE para atajar los riesgos de una nueva recesión en la zona euro. El BCE había de renunciar a los fantasmas de la «estanflación» para sumergirse en la heterodoxia. Una medida de política monetaria que desagradaba a las autoridades germanas que insisten en que los tratados prohíben expresamente financiar a los Estados. Sin embargo, la medida va destinada a que la inflación se vaya acercando al $2 \%$, objetivo central que estaba incumpliendo el BCE. Así, Draghi señalaba, en marzo de 2015, que la fecha de septiembre de 2016 era orientativa y que el programa de compras podría prolongarse hasta que la inflación se fuera acercando a ese objetivo del $2 \%$. El pronunciamiento del BCE propició, antes de que se activase realmente el plan de compra de deuda, una fuerte depreciación del euro. Cotizaba a 1,07 dólares a principios de marzo cuando estaba a 1,24, en noviembre de 2014, y 1,42 en la primavera de 2012. Esa depreciación estimularía el crecimiento económico y el empleo, vía aumento de las exportaciones, e induciría un repunte marginal de la inflación vía encarecimiento de las importaciones. Por otra parte, se compraban casi todos los activos que gozaran de «grado de inversión», primándose la deuda a 10 años. Solo quedaban fuera los bonos basura, si bien el presidente del BCE añadió que «algunos criterios adicionales se utilizarán en los países bajo programas de la UE y el FMI». Al referirse a activos con grado de inversión, quedaría excluida Grecia si no se garantizaba un programa de la Troika. Asimismo, evitar el conflicto con Alemania y otros países de su entorno le ha llevado a comprar deuda de todos los miembros de la eurozona según su participación en el capital del $\mathrm{BCE}^{27}$. Solo así se veía autorizado a inyectar abultadas cantidades en la periferia europea. Si bien Alemania era el país más beneficiado a nivel cuantitativo por las compras del BCE, era el que menos las necesitaba toda vez

27 El BCE destina el $12 \%$ a comprar deuda española, casi el $24 \%$ a la compra de deuda alemana, algo más del $18 \%$ a la deuda gala y cerca del $14 \%$ a la deuda italiana. Sí bien, por ejemplo, la aportación de España al capital social de la institución es de casi 1.000 millones de euros, lo que representa un $8,84 \%$, el porcentaje mayor de compra de bonos se debe a que los 19 países de la Eurozona tienen un $70 \%$ del capital de la entidad, pero se reparten el $100 \%$ del programa de compra de activos. 
que ya lograba colocar toda su deuda en los mercados, incluso a tipos negativos en plazos entre 2 y 5 años, y por debajo del $1 \%$ los títulos con vencimiento a 10 años. Se hallaba, asimismo, planteado el problema de quién asumía el riesgo de solvencia. Para las autoridades alemanas, los bancos centrales nacionales habían de introducir en sus respectivos balances el importe principal de las compras de deuda pública de sus propios países para que los contribuyentes alemanes no tuvieran que soportar las consecuencias de eventuales pérdidas de valor en la deuda pública de otros países con los que comparten moneda. Así el BCE acordó que el grueso de la operativa transitase a través de cada uno de los 19 bancos centrales. En caso de pérdidas, la mutualización, pérdidas compartidas, se limita al 20\%, y el $80 \%$ está sujeto a un riesgo de insolvencia asumido por los gobiernos que se beneficien de la compra de activos. Al no existir una mutualización real de riesgos, se evidencia que la política monetaria es solo teóricamente única. El BCE introduce una clara diferenciación de calidad crediticia, y los países más débiles, como se ha visto en Grecia, quedan expuestos a la reacción adversa de los mercados cuando surgen situaciones de incertidumbre. Así, por ejemplo, el destino del sistema bancario griego, y por tanto del propio país, depende de la buena voluntad del BCE y de que dé continuidad a la financiación de urgencia (EmergencyLiquidityAssistance). Esa financiación, tras ser congelada, fue elevada una vez decidiera el gobierno griego, después del sorprendente referéndum, rendirse sin condiciones al programa impuesto por las Instituciones y destinar los recursos del crédito puente concedido por los socios europeos a pagar los vencimientos inmediatos tanto al BCE como al FMI. El Presidente del BCE afirmaba que «Se han restaurado las condiciones para aumentar la línea de liquidez de emergencia a la banca griega».

Las compras de bonos persiguen también dar más capacidad al sistema financiero para aumentar el crédito al sector privado. El objetivo es que pierda su apetito por la deuda pública y destine los recursos a financiar inversiones más rentables en la economía productiva. Al comprar el $\mathrm{BCE}$ bonos soberanos de forma masiva, sus precios suben y su rentabilidad - que ya se encuentra en mínimos históricos - debería bajar aún más. Además, viéndose impulsados los bancos a vender deuda pública, una vez su precio se halla en niveles máximos y mínima su rentabilidad, la liquidez conseguida podría ir destinada a comprar bonos corporativos y acciones y/o conceder créditos a familias y empresas. Los bancos tendrían pues que asumir un mayor riesgo y conceder créditos al sector privado, sí bien las nuevas normas de solvencia y de liquidez impuestas por Basilea III traban la apertura del grifo del crédito. Además, los efectos de estas compras sobre la economía real pueden quedar diluidos toda vez que los agentes privados ya están sobreendeudados, priman la estrategia de desapalanca- 
miento y se resisten a pedir prestado, por abundante y barata que esté la liquidez. Como apuntara Keynes, si el caballo no tiene sed no bebe por mucho que se le lleve al abrevadero. De ahí se deduce la preferencia por la liquidez debido al bajo rendimiento de los bonos y a que se anticipa una caída de su precio en cuanto se recupere la economía. De ahí deriva también la «paradoja del ahorro». Wolf denuncia el simplismo del razonamiento liberal que obvia que los nuevos deudores no son los mismos que los antiguos. «Es necesario que el solvente se endeude cuando aquellos que ya no son solventes no pueden hacerlo. Si todo el mundo trata de cortar su endeudamiento y su gasto al mismo tiempo, el resultado será una depresión: esa es la «paradoja del ahorro», expresión popularizada por el premio Nobel Paul Samuelson ${ }^{28}$. Según Keynes, cuando los agentes se decantan por el ahorro, se contraen la demanda, la producción y las rentas. A su vez, esta pérdida de rentas produce un efecto retorno negativo tanto en el consumo como en el propio ahorro. Y, la producción y las rentas seguirán cayendo hasta que el ahorro deseado se ajuste a la inversión. Sin embargo, la magnitud de esta última variable también ha caído mientras se contraía la economía. Así pues, paradoja: un mayor apetito por el ahorro puede alentar una profunda recesión de la que resulta difícil escapar, y resulta tanto más difícil salir de este círculo vicioso cuando los tipos de referencia del banco central son cercanos a cero. Lo que lo fía todo, opción descartada en la eurozona, al impulso fiscal.

Otro objetivo perseguido por el QE es aliviar el coste de endeudamiento de los Estados. Pero, ¿qué sentido tiene recortar más la rentabilidad de una deuda pública que se situaba en el 0,2\% para los bonos a 10 años en Alemania en marzo de 2015 o en el 1,2\% en España, unos niveles históricamente bajos? ¿Resulta congruente que las economías española y portuguesa, cuyos fundamentos distan de ser equiparables a los norteamericanos, y que han tenido que ser rescatadas total o parcialmente, emitan a coste menor que Estados Unidos? La lluvia de liquidez en el mercado ha distorsionado tanto los precios de los activos que las primas se ven más afectadas por el sesgo expansivo de la nueva política monetaria que por los «fundamentales» de la economía de la zona euro. ¿Es sostenible esta situación artificial que se observa en el mercado de la deuda? El BCE parece haberse decantado por compras masivas de deuda pública cuando ya no era necesario, más aún, habida cuenta la depreciación del euro, que se ha visto, no obstante, precipitada por el anuncio de compras masivas de activos por el BCE. Prueba de que este programa ya no era tan necesario es que, aunque la crisis griega ha influido en ello, la rentabilidad de los bonos ha subido de forma mode-

28 WOLF, M., op. cit.,nota 6, p. 91. 
rada desde el inicio de las compras. Lo cual no es negativo. En efecto, los mercados se habían anticipado al anuncio y habían proyectado a la política económica hacia zonas desconocidas no exentas de riesgos al colocar los tipos de interés de las nuevas emisiones en terreno negativo o cuasi negativo. En contra de lo habitual, situación cuando menos anómala por mucho que se invocara que los precios en la zona euro estaban creciendo a tasa negativa $(-0,3 \%$ en marzo de 2015$)$ y que, por lo tanto, los tipos reales seguían siendo positivos, los inversores habían pasado a pagar por prestar dinero a los Estados. Los planes de expansión cuantitativa, siendo el BCE el último de los grandes bancos en llegar a ellos, han provocado una distorsión inaudita del mercado de deuda y son susceptibles de inducir una burbuja en los mercados de renta fija que compromete la estabilidad financiera. Así pues, aun cuando el descenso de los intereses era uno de los objetivos perseguidos, no deja de preocupar un retroceso tan pronunciado que desemboca en tipos negativos que acercan, por otra parte, al BCE a sus propios topes. En efecto, no comprará bonos con un rendimiento inferior a los tipos de depósito, situados en el $-0,2 \%$ ¿ No saldrán cada vez más bonos de su radar según se intensifiquen las compras? El riesgo de este QE tardío reside en que los efectos sean más pronunciados en los precios de los activos financieros que en la economía real.

Parece que los gobernantes europeos se equivocan al focalizar su atención sobre la política monetaria y al magnificar sus potencialidades. El impacto del QE sobre la inflación y la actividad va a ser menor al alcanzado en Estados Unidos debido a que los tipos de interés ya están en cero y, además, la financiación de las empresas norteamericanas es más tributaria de los mercados de capitales respecto de las empresas de la zona euro. La solución a los males europeos pasa más por los estímulos fiscales para reactivar la demanda y la demanda de crédito, y por concretar los proyectos paneuropeos invocados por Juncker y dotarlos de recursos reales significativos ${ }^{29}$. Como apuntó Bernanke, la recuperación es más débil cuando las políticas fiscales y monetarias trabajan en direcciones opuestas. Sin embargo, a partir de 2013, una vez «descubren» la Comisión Europea y el FMI que los multiplicadores de crecimiento estaban equivocados y que su política de austeridad extrema solo generaba más recesión, la guía política está siendo suavemente alterada. La referencia prioritaria ya no es tanto la estabilidad del déficit sino el mantra de las «reformas estructurales», léase la mayor flexibilidad laboral. Así, en un foro convocado en Sintra los días 22 y 23 de mayo de 2015, el vicepresidente de la Fed, Stanley Fischer, no dudaba en cuestionar la insistencia de Draghi en reclamar reformas estruc-

29 AGLIETTA, M. y BRAND, T., op. cit., nota 14. 
turales a los países europeos: «Un banquero central puede pedir reformas como la laboral muy de vez en cuando; pero no puede convertirlas en su principal argumento cada vez que habla». Draghi se justificaba aduciendo: «No puedo evitar responder a los lamentos sobre la falta de legitimidad del BCE para reclamar reformas o medidas de política fiscal. Son vitales para que no crezcan las divergencias dentro de la unión monetaria: a largo plazo eso haría inviable el euro, y la primera obligación del BCE es mantener el euro intacto». En realidad, la causa de las aparentes incongruencias e impertinencias de la política monetaria del BCE fue apuntada, en 2012, por Bergsten.

«De hecho, ni Alemania ni el BCE tienen intención de poner fin a la crisis con rapidez. Su objetivo es, más bien, servirse de la crisis para realizar las reformas económicas adicionales necesarias para crear una economía europea fuerte a largo plazo. Esto ayuda a explicar la razón por la cual las autoridades de la zona euro no han creado un cortafuegos financiero tan importante como el que reclamaban los mercados» ${ }^{30}$.

Además, lo que dificulta las labores del BCE, la vía de ajuste destinada a potenciar la competitividad externa mediante depreciación salarial, choca contra un escollo difícil de sortear. No sólo los precios caen (o se estancan) en España, Grecia o Portugal, sino que apenas suben en los países centrales del euro, lo que impide reabsorber la desventaja competitiva de la periferia. Como apunta Wolf, «la dispersión en inflación entre países acreedores y deudores necesaria para acelerar el ajuste en la competitividad no está sucediendo suficientemente rápido, porque el nivel de inflación es demasiado bajo» ${ }^{31}$.

Las señales de cambio son pues confusas y sigue imperando la lógica subyacente a las políticas de oferta. La austeridad fiscal va a ser mantenida en lo sustancial siendo, no obstante, atenuado su impacto contractivo por una política monetaria más acomodaticia cuyo éxito es tributario de que sus efectos expansivos se transmitan a la economía real, sobre todo a las Pymes. El entramado ortodoxo de la política actual descansa sobre la creencia ingenua que la bajada de los tipos de interés aplicados a la deuda soberana conllevará una bajada mecánica de los tipos soportados por los agentes privados. Además, este recorte de los tipos debería acelerar la depreciación del tipo de cambio y, de verificarse la teoría de las expectativas racionales, los hogares van a recortar su ahorro e incrementar su

30 BERGSTEN, F. y RUIZ, J.J., «Por qué el euro sobrevivirá» en Política Exterior, n. ${ }^{\circ}$ 150, 2012, pp. 110-120, p. 112.

31 WOLF, M., op. cit.,nota 6, p. 433. 
consumo al anticipar un recorte de sus impuestos Así pues el multiplicador pasa a ser inferior a 1 , y es amortizado el shock de austeridad ${ }^{32}$. Pero, pese al credo defendido por los fundamentalistas de la austeridad, esta, debido al juego adverso de los multiplicadores, ha agravado la caída del PIB, ha provocado un nuevo deterioro de la ratio deuda/PIB (extremo en el caso de Grecia cuyo PIB ha caído un 25\%, entre 2010, y mediados de 2015) y, consecuencia de ello, ha sido que los spreads sobre los tipos de interés han empeorado en lugar de remitir. Ello ha socavado la capacidad de los países para hacer frente al servicio de su deuda ${ }^{33}$, hasta que el BCE se ha decidido a romper con una ortodoxia trasnochada. De hecho, ha quedado demostrado, en cuanto se ha explicitado, a partir de julio de 2012, que las deudas de los Estados eran susceptibles de ser asumidas por el BCE, que no tenían razón de ser las abultadas primas de riesgo país soportadas por la periferia europea. Queda por ver si la monetización de hecho de una parte de la deuda y la constatación de que las políticas «austericidas» han fracasado serán elementos aprovechados para alentar una política presupuestaria neutra o incluso de reactivación ${ }^{34}$.

\section{Conclusiones}

Las crisis sucesivas se han encargado de demostrar que una política monetaria diseñada bajo un único mandato está mal equipada y que la obsesión manifestada hacia la estabilidad de los precios, aparte de ser irracional en el actual marco de competencia global, susceptible de desembocar en una deflación destructiva, puede acarrear unas pérdidas permanentes de producción y empleo. La erradicación del paro, en contra de la lógica de ajuste subyacente al proyecto inacabado de UME, debería ser la prioridad, aunque ello implicara tolerar una mayor inflación residual de salarios y precios. También nos señalan estas crisis que la salida de las mismas no provendrá de menores salarios, sino de una mejora de la productividad lograda mediante más innovación y tecnología, y nos revelan, asimismo, que la política monetaria tiene una capacidad de respuesta más limitada cuando no se coordina con la fiscal, cuando los tipos de in-

32 AGLIETTA, M., Europe: sortir de la crise et inventer l'avenir, Michalon, París, 2014, pp. 46-47.

${ }^{33}$ MUÑOZ DE BUSTILlO, R., «La crisis del nunca acabar. El comportamiento macroeconómico español 2008-2013» en ¿Qué ha pasado con la economía española?, editado por Norberto García y Santos Ruesga, Pirámide, Madrid, 2014, pp. 55-82, p. 71.

${ }^{34}$ TIMBEAU, X., «Retour à la récession» en Alternatives Économiques, Hors-série n. ${ }^{\circ}$ 92, 2. ${ }^{\circ}$ trimestre 2012, p. 22. 
terés oficiales están en cero y, como ocurre en la zona euro, el sistema financiero presenta grandes debilidades. Estas crisis han evidenciado, por otra parte, que las medidas impulsadas por el BCE aspiran a atajar el problema de la restricción crediticia desde el punto de vista de la oferta, pese a que el escaso crecimiento del crédito responde, sobre todo, a problemas desde la demanda. Las familias y empresas siguen muy endeudadas, el paro es masivo, los salarios se contraen, la precariedad es ascendente, y las perspectivas de negocio siguen siendo modestas. Todo ello limita la posibilidad de un nuevo endeudamiento, así como impide que los bancos puedan prestar con las garantías suficientes. Ello restringe seriamente el alcance del multiplicador monetario por acomodaticia que sea la política monetaria. La normalización del crédito es, ante todo, tributaria de que mejore la economía y la situación financiera de las familias y empresas. Por otra parte, el actual programa de estímulo cuantitativo ha surgido cuando menos necesario era toda vez que, salvo Grecia, cuya supervivencia depende de la buena voluntad del BCE, los tipos de interés aplicados a las deudas públicas se hallan en unos niveles históricamente bajos en sus diversos plazos.

Asimismo, siendo por ahora Grecia el más claro exponente de ello, tras haber sido receptores de sorprendentes misivas del BCE los presidentes de los gobiernos español (agosto 2011)e italiano ${ }^{35}$, la independencia del BCE, que no duda en reducir a la nada la independencia de las más altas instituciones políticas, incluidos los parlamentos, solo apuntala el poder ascendente de los mercados financieros frente a las elecciones democráticas ${ }^{36}$. La experiencia del BCE es extrapolada para sugerir que la eficiencia del sistema requeriría que fueran creadas unas instituciones y agencias independientes del poder político en el orden presupuestario.Pero, ¿es neutra la política de los bancos centrales cuyo eje prioritario es la salvaguarda de los intereses de los grandes bancos internacionales? ¿Está inscrito en el orden natural de las cosas que el BCE pueda determinar la políticaeconómica de los gobiernos y que estos ni siquiera puedan formularle sugerencias en cuanto a la oportunidad de su política ${ }^{37}$ ? El carácter ilusorio de la mal llamada independencia ha sido denunciado con clarividencia y contunden-

35 Se les exigía una liberalización radical de la economía, un cuestionamiento de la negociación colectiva que privilegiase los acuerdos de empresa respecto de los de ámbito superior, aligerar los procesos de despido y abaratar sus costes, endurecer la consolidación presupuestaria contrayendo los gastos de pensiones y prestaciones varias, la constitucionalización del equilibrio presupuestario, etc. El BCE al servicio del credo neoliberal que ha llevado a la eurozona al fracaso económico más estrepitoso.

36 FITOUSSI, J.P., La democracia y el mercado, Paidós, Barcelona, 2004, p. 91.

37 RODRÍGUEZ ORTIZ, F., Las máscaras de la crisis: Europa a la deriva, Los Libros de la Catarata, Madrid, 2012. 
cia por Martín Seco:«Lo cierto es que la independencia casi nunca existe, y cuando a una institución se la libera del poder democrático y del control de los ciudadanos, termina dependiendo de otros intereses y poderes mucho más bastardos» ${ }^{38}$. El problema de la eurozona, que prima una gobernabilidad débil e inestable mediante los mercados, es que los países de la zona euro se hallan en situación de ser unos Estados federados huérfanos de un Estado federal, lo que impide que la Unión pueda ser una unión de transferencias. La integración mediante los mercados de bienes y de capitales ha creado en la zona euro unas fuertes interdependencias que ninguna institución pública es capaz de gestionar ${ }^{39}$.

«Al privilegiar un modo de integración tendente a encerrar las prerrogativas de los Estados en unas normas cada vez más restrictivas y coercitivas, la Unión Europea ha vaciado poco a poco de contenido a la soberanía nacional sin por ello impulsar una soberanía europea. Así pues, el gobierno de Europa es mucho más un gobierno mediante las reglas que un gobierno mediante las elecciones (choix) $\gg^{40}$.

En definitiva, y basta para convencerse de ello observar la evolución dispar de Estados Unidos y de la zona euro, la gestión de las crisis nos revela las bondades y aciertos de la «vieja» macroeconomía keynesiana respecto del «joven»e «innovador» neoliberalismo, cuyos paradigmas centrales son más desregulación y moderación salarial, apología de la «restricción presupuestaria expansiva» y rechazo a las políticas monetarias expansivas por temor a la inflación. Como apunta Krugman ${ }^{41}$ :

«Puede que los responsables políticos europeos creyesen que estaban mostrando una apertura a las nuevas ideas económicas digna de elogio, pero los economistas a los que decidieron escuchar eran aquellos que les decían lo que querían oír. Trataron de justificar las estrictas medidas que, por razones políticas e ideológicas, estaban decididos a imponer a los países deudores... Y mientras las nuevas ideas se estrellaban y ardían, la economía de antaño cobraba cada vez más fuerza. Puede que algunos lectores recuerden la cantidad de burlas que hubo hacia las predicciones de los economistas keynesianos, yo entre ellos, que decíamos que los tipos de interés se mantendrían bajos aunque el déficit presupuestario fuese enorme; que la inflación seguiría estando controlada

38 MARTÍN SECO, J.F., op. cit., nota 7, p. 31.

39 CHEVALLIER, A., «L'économie mondiale cinq ans après la crise financière», en L'économie mondiale 2013, editadoporCEPII, La Découverte, París, 2012, pp. 5-19, p. 7.

${ }^{40}$ FITOUSSI, J.P., op . cit.,nota 8, p. 126.

${ }^{41}$ KRUGMAN, P., «La ciencia económica de antaño» en El País-Negocios, Madrid, 18 abril 2015 . 
aunque la Reserva Federal comprase grandes cantidades de bonos; que los recortes drásticos del gasto público, lejos de generar un boom económico debido a la confianza, hundirían todavía más el gasto privado. Pero todas estas predicciones se cumplieron. La cuestión es que es un error afirmar, como hacen muchos, que la política fracasó porque la teoría económica no brindó a los responsables políticos la orientación que necesitaban. En realidad, la teoría ofrecía unas directrices excelentes, si los políticos hubiesen estado dispuestos a escucharlas. Por desgracia, ni lo estaban, ni lo están».

\section{Bibliografía}

AGLIETTA, M., Zone euro: éclatement ou fédération, Michalon, París, 2012.

- Europe: sortir de la crise et inventer l'avenir, Michalon, París, 2014.

- «Dette publique et politique monétaire dans la zone euro» en L'Économiemondiale 2015, editado por CEPII, Paris, La Découverte, 2014, pp. 24-42.

AGLIETTA, M. y BRAND, T., Un new deal pour l'Europe, Odile Jacob, París, 2013.

ANGUSTO, J., ¿Y ahora qué? Entre la crisis y la miseria: propuestas alternativas, Gregal, Barcelona, 2013.

ARTUS, P. y GRAVET, I., La crise de l'euro, Armand Colin, París, 2012.

BERGSTEN, F. y RUIZ,J.J.,«Por qué el euro sobrevivirá» enPolíticaExterior, n. ${ }^{\circ}$ 150, 2012, pp. 110-120.

BETHĖZE, J.P., BORDES, C., COUPPEY-SOUBEYRAN, J. y PLIHON, D., Banques centrales et stabilité financière, Conseil d'Analyse Économique, La Documentation Française, París, 2011.

BLYTH, M., Austeridad: historia de una idea peligrosa, Crítica,Barcelona, 2014.

BOYER,R., Les financiers détruiront-ils le capitalisme?, Economica, París 2011.

COSSART, J., DOURILLE-FEER, E., HARRIBEY, J.M., HUSSON, M., JEFFERS, E., KHALFA, P., MATH, A., PLIHON, D. y TOUSSAINT, E., Le piège de la dette publique, Les Liens qui Libèrent, París, 2011.

CHEVALLIER, A., «L'économie mondiale cinq ans après la crise financière», en L'économie mondiale 2013, editado por CEPII, La Découverte, París, 2012, pp. 5-19

FITOUSSI, J.P., La democracia y el mercado, Paidós, Barcelona, 2004.

- Le théorème du lampadaire, Les Liens qui libèrent, París, 2013.

GRAUWE, P. y JI, Y., «More evidence that financial markets imposed excesive austerity in the eurozone» en CEPS, 5 febrero 2013.

GREAU, J.L., La Grande Récession (depuis 2005), Folio, París, 2012.

JEFFERS, E., LE HERON, E. y PLIHON, D.» Pour une Banque centrale européenne au service de l'intérêt général» en Changer l'Europe, Les Économistes Atterrés,Les Liens qui Libèrent, París, 2013, pp. 239-256.

KRUGMAN, P., «La ciencia económica de antaño» en El País-Negocios, Madrid, 18 abril 2015. 
LE HERON, E., À quoi sert la Banque centrale européenne?, La Documentation Française, París, 2013.

MARTÍN SECO, J.F., Contra el euro: historia de una ratonera, Península, Barcelona, 2013.

MUÑOZ DE BUSTILLO, R., «La crisis del nunca acabar. El comportamiento macroeconómico español 2008-2013» en ¿Qué ha pasado con la economía española?, editado por Norberto García y Santos Ruesga, Pirámide, Madrid, 2014, pp. 55-82.

O'ROURKE, K. y TAYLOR, A., «Cross of euros» en Journal of Economic Perspectives, vol.27, n. ${ }^{\circ}$ 3, 2013, pp. 167-192.

RODRÍGUEZ ORTIZ, F., La Unión Monetaria y España: ¿Integración económica odesintegración social?, Ed. Universidad de Deusto, Bilbao, 1997.

- Crisis de un capitalismo patrimonial y parasitario, Los Libros de la Catarata, Madrid, 2010.

- Las máscaras de la crisis: Europa a la deriva, Los Libros de la Catarata, Madrid, 2012.

TIMBEAU, X., «Retour à la récession» en Alternatives Économiques, Hors-série n. ${ }^{\circ} 92,2 .^{\circ}$ trimestre 2012.

- «Le commencement de la déflation. Perspectives 2013-2014 pour l'économie mondiale» en Revue de l'OFCE, n. ${ }^{\circ}$ 129, Presses de Sciences Po, avril 2013.

WOLF, M., La gran crisis: cambios y consecuencias, Ed. Deusto, Barcelona 2015. 


\section{Derechos de autor (Copyright)}

Los derechos de autor de esta publicación pertenecen a la editorial Universidad de Deusto. El acceso al contenido digital de cualquier número de Cuadernos Europeos de Deusto (CED) es gratuito, transcurridos 6 meses desde su publicación. Los trabajos podrán descargarse, copiar y difundir, sin fines comerciales y según lo previsto por la ley. Así mismo, los trabajos editados en CED pueden ser publicados con posterioridad en otros medios o revistas, siempre que el autor indique con claridad y en la primera nota a pie de página que el trabajo se publicó por primera vez en CED, con indicación del número, año, páginas y DOI (si procede). 